\title{
Comparative performance of composite sandwich panels and non-composite panels under blast loading
}

\author{
Vasant A. Matsagar
}

Received: 27 June 2014/Accepted: 3 January 2015/Published online: 14 January 2015

(C) The Author(s) 2015. This article is published with open access at Springerlink.com

\begin{abstract}
The performance of non-composite panels built of steel plates, concrete slabs, and composite sandwich panels in blast response reduction is examined and compared in the present study. The dynamic response of steel stiffened and unstiffened plates, plain concrete, reinforced concrete, and steel fiber reinforced concrete slabs, stiffened and unstiffened steelfoam-steel, and steel-sand-steel sandwich panels is investigated through three-dimensional finite element analyses. Parametric studies are performed considering different stiffener configurations, panel thicknesses, materials in the composite sandwich panels (e.g. polyurethane, dytherm, cenosphere aluminum alloy syntactic foams, and sand), and varying thicknesses of foam and sand layers. Strain rate dependent material properties for steel, concrete, steel fiber reinforced concrete, foams, and sand are used in the analyses. Blast load is modeled using an equivalent pressure time history curve calculated as per the TM51300 manual and the modified Friedlander's equation. The central node displacement of the panels for peak blast overpressure $1.16 \mathrm{MPa}$ applied for $6.1 \mathrm{~ms}$ is studied. The results indicate that the non-composite panels made up of steel fiber reinforced concrete slabs and cenosphere aluminum alloy syntactic foam
\end{abstract}

V. A. Matsagar $(\bowtie)$

Department of Civil Engineering, Indian Institute of Technology (IIT) Delhi, Hauz Khas, New Delhi 110 016, India

e-mail: matsagar@civil.iitd.ac.in composite sandwich panels show excellent blast response reduction capability as compared to (a) steel plate, (b) plain and reinforced concrete slabs, and (c) polyurethane and dytherm foam cored composite sandwich panels.

Keywords Blast - Concrete slab - Composite sandwich foam panel - Composite sandwich sand panel $\cdot$ Steel $\cdot$ Steel fiber reinforced concrete $\cdot$ Strain rate

\section{Introduction}

In the twentieth century, blast has become the most severe manmade hazard that civil and military infrastructure may be subjected to as a result of terror attacks. Till the date, different materials have been used for blast response mitigation in structures such as polymeric foams, sand, fiber reinforced polymer (FRP) composites, porous materials, metal foams, sandwich structures and similar. Protective structures against blast loading include stiffened and unstiffened steel, reinforced concrete panels, and sandwich structures that can dissipate large amount of energy by plastic deformation under blast loading [1-6]. In the literature, several experimental and numerical studies exist on unstiffened and stiffened steel plates, composite armours, reinforced concrete panels and sandwich structures under blast loading [7-19]. However, a 
comprehensive study on the comparative performance of different materials under blast loading is not available in the literature.

The objectives of the present study are to examine (i) the deformation and energy response of noncomposite panels built of stiffened and unstiffened plates, slabs, and composite sandwich structures under blast loading, and (ii) to identify the material that shows maximum blast response reduction capability from the selected cases. In the present study, threedimensional (3D) finite element (FE) analyses have been performed using the commercial finite element software Abaqus 6.11 [20] to investigate the capability of blast response reduction for different materials. Analyses are performed for (a) stiffened and unstiffened steel plates, (b) plain concrete (PC), reinforced concrete (RC) and steel fiber reinforced concrete (SFRC) slabs, and (c) stiffened and unstiffened composite sandwich panels, e.g., (i) steel-polyurethane foam-steel (SPS), (ii) steel-dytherm foam-steel (SDS), (iii) steel-cenosphere aluminum alloy syntactic foam with the average size of cenosphere $90 \mu \mathrm{m}$ (AlFoam90)-steel (SAS90), (iv) steel-cenosphere aluminum alloy syntactic foam with the average size of cenosphere $200 \mu \mathrm{m}$ (AlFoam200)-steel (SAS200), and (v) steel-sand-steel (SSS) panels under blast loading. Figure 1a presents the cases considered for analysis in the present study. Parametric studies have been carried out using (i) ten different stiffener configurations for steel and sandwich panels, (ii) three different thicknesses $\left(t_{\mathrm{p}}\right)$ of the PC, RC, and SFRC slabs, and (iii) three different core thicknesses $\left(t_{\mathrm{c}}\right)$ of the sandwich panels under blast loading.

\section{Model and material properties}

Square steel plates, concrete slabs, and composite sandwich panels of size $2 \mathrm{~m} \times 2 \mathrm{~m}$ have been considered in the present study for analyses. The finite element models are prepared using Abaqus/CAE. Unstiffened steel plate $\left(\mathrm{P}_{1}\right)$ of thickness $\left(t_{\mathrm{p}}\right) 20 \mathrm{~mm}$ and three concrete slab thicknesses $\left(t_{\mathrm{p}}\right)$ of 100, 150, and $200 \mathrm{~mm}$ for each slab type (e.g., PC, RC, and SFRC) have been considered. The dimensions are chosen based on the common sizes of the construction facilities in the field. Ten different stiffener configurations $\left(\mathrm{P}_{2}\right.$ to $\left.\mathrm{P}_{11}\right)$ have been considered for stiffened steel plates. The stiffeners are $100 \mathrm{~mm}$ in width and
$10 \mathrm{~mm}$ in thickness for all the configurations. The stiffened steel plates are constructed by removing material from a thick blank (this is different from a plate with extra stiffeners added typically by welding material onto the plate). Thus, the sheet and stiffeners are in perfect contact. The stiffened steel plates with ten different stiffener configurations $\left(\mathrm{P}_{2}\right.$ to $\left.\mathrm{P}_{11}\right)$ and one unstiffened steel plate $\left(\mathrm{P}_{1}\right)$ are shown in Fig. $1 \mathrm{~b}$. The plates $P_{1}$ to $P_{11}$ are arranged and named as per increasing weights of the panels. The PC slabs have been modeled using concrete grade M25 having quasistatic compressive strength of $25 \mathrm{MPa}$ with and without minimum reinforcement. The minimum reinforcement cross-sectional area has been calculated using Indian standard code IS 456 (2000) [21] as $0.12 \%$. The reinforcement has been modeled with $10 \mathrm{~mm}$ diameter steel reinforcement bar. For the RC slabs, $0.25 \%$ steel reinforcement and $10 \mathrm{~mm}$ reinforcement bar diameter are modeled. The chosen reinforcement percentage has shown satisfactory performance under blast loading in the previous studies [10]. The material properties of concrete and steel are given in Table 1. The SFRC slabs are assumed to consist of $3 \%$ steel fiber by volume. According to the earlier investigations [22], under strain rate dependent loading such as that due to blast, $3 \%$ steel fiber by volume exhibits higher strength as compared to 0 and $6 \%$ steel fiber by volume. The SFRC slabs have been modeled both with and without reinforcement. The minimum reinforcement cross-sectional area has been calculated using Indian Standard Code IS 456 (2000) [21] as $0.12 \%$. The reinforcement has been modeled with $10 \mathrm{~mm}$ diameter reinforcement bar.

The composite sandwich panels consist of one face sheet and one stiffened or unstiffened back sheet, both made of steel and each of $10 \mathrm{~mm}$ thickness, with a foam/sand core in between. One unstiffened $\left(\mathrm{P}_{1}\right)$ and ten stiffened $\left(\mathrm{P}_{2}\right.$ to $\left.\mathrm{P}_{11}\right)$ back sheets have been considered in the present investigation with four types of foam cores namely, polyurethane, dytherm, and cenosphere aluminum alloy syntactic foam with the average sizes of cenosphere 90 and $200 \mu \mathrm{m}$ (SAS90 and SAS200). Composite sandwich panels with sand core have also been analyzed. The foam and sand cores are taken in their thicknesses of 50, 100, and $150 \mathrm{~mm}$ for each type. The thicknesses of face and back sheets and foam/sand have been decided based on the blast response study of these panels carried out by Goel et al. [4, 23]. Figure 1c shows a typical finite 
(a)

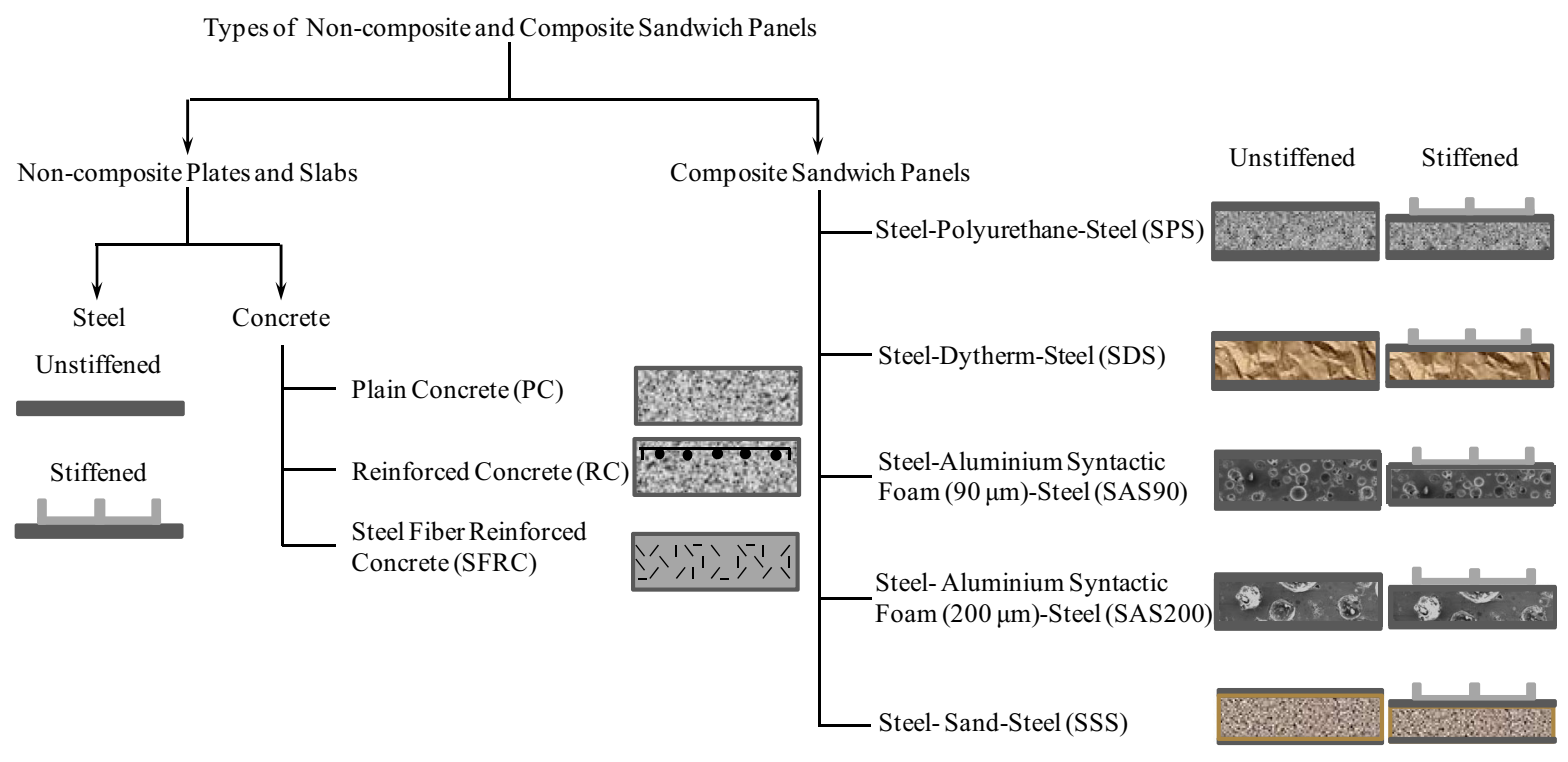

(b)

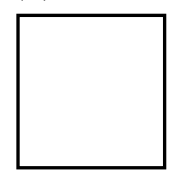

$\mathrm{P}_{1}$

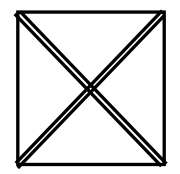

$\mathrm{P}_{5}$

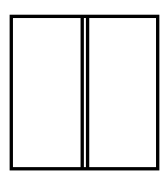

$\mathrm{P}_{2}$

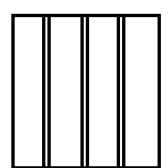

$\mathrm{P}_{6}$

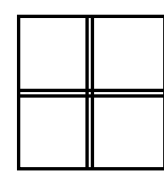

$\mathrm{P}_{3}$

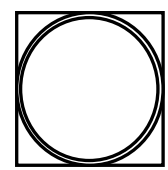

$\mathrm{P}_{7}$

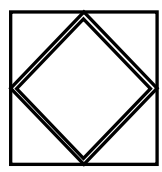

$\mathrm{P}_{4}$

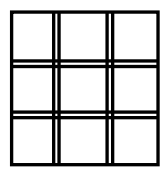

$\mathrm{P}_{8}$

(c)

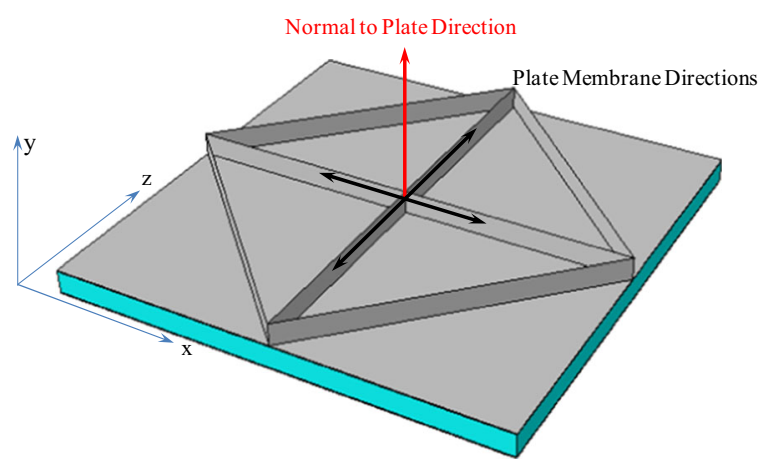

Fig. 1 a Cases for parametric studies, b Plate and panel configurations arranged with increasing weights, c Stiffened composite sandwich panel model $\left(\mathrm{P}_{9}\right)$

element model of stiffened composite sandwich panel with panel normal direction.

\subsection{Finite element modeling}

The finite element models of the steel plates and the stiffeners consist of linear, finite-membrane strain, reduced integration, four node quadrilateral shell elements (S4R) with hourglass control available in Abaqus. The geometry of the foam/sand core is modeled using the eight-node linear brick elements with reduced integration and hourglass control (C3D8R). More details about these elements may be found in Belytschko et al. [24], Nascimbene and Venini [25]. Element size for the steel and the composite sandwich panels have been selected $5 \mathrm{~cm}$ based on the mesh convergence study performed by 


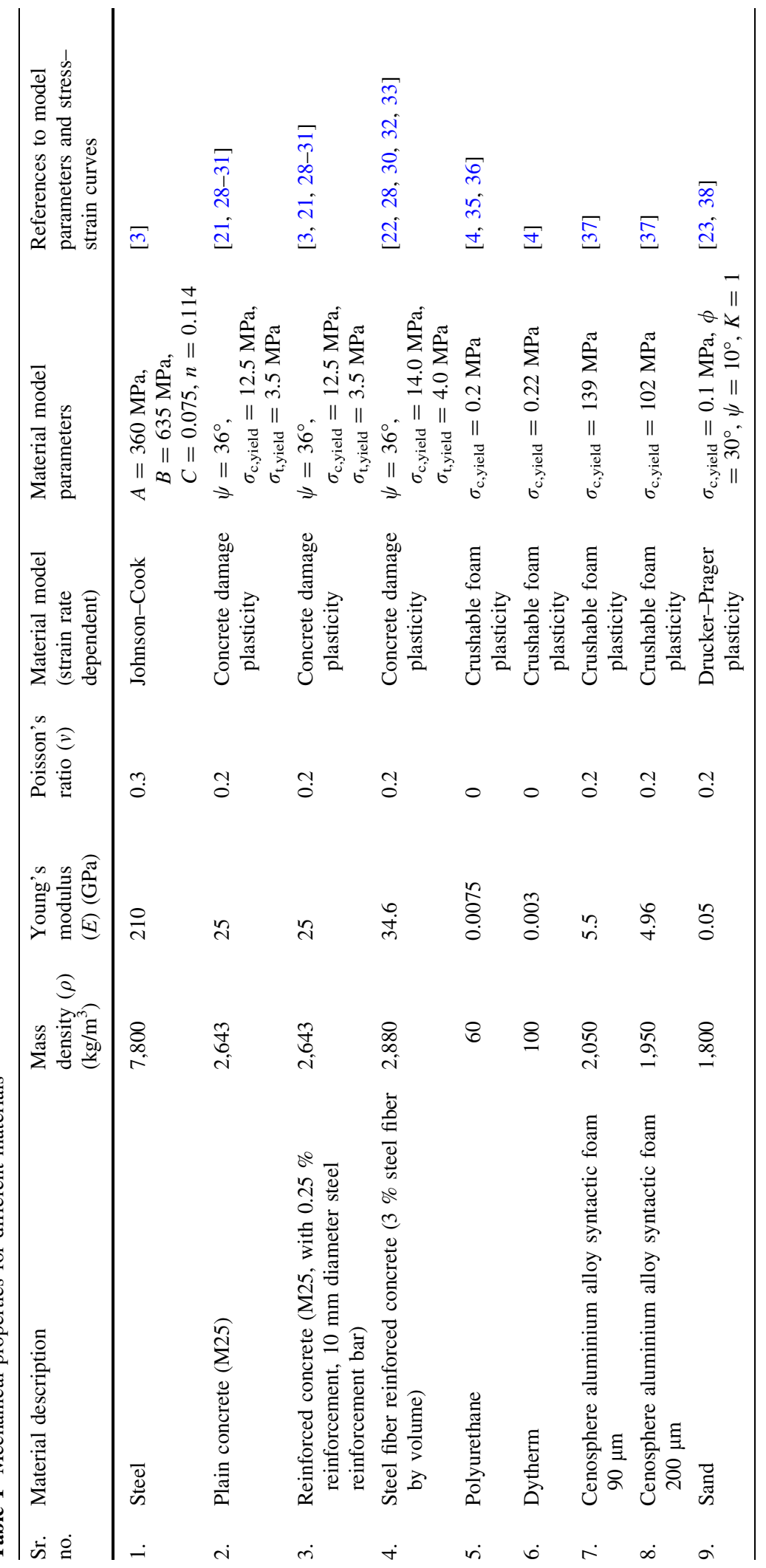


Goel et al. [3, 4, 23]. For the concrete slabs, the element size has been chosen $1 \mathrm{~cm}$ decided through mesh convergence performed by Tiwari et al. [10]. The interfaces between different layers of the composite sandwich panels are considered to be in perfect contact without delamination. For foam cores, hard contact in normal direction and frictionless contact in tangential direction are assumed; for sand core, rough tangential contact is considered. The reinforced concrete slab is modeled using the S4R element with rebar layers for the reinforcement bars. Clamped boundary conditions are applied on all the edge nodes along the side surface. The blast loading is applied on the unstiffened side of the steel plate, opposite to the reinforced side of the RC slabs, and on the face sheet for the composite sandwich panels. Material and numerical damping have not been used in any of the analyses presented herein.

The validity of the finite element (FE) models has been ensured for steel plates, concrete slabs, and composite sandwich panels under blast loading by comparing the numerical simulation results with the experimental data and analysis results obtained from the literature. The validation studies have been reported in Goel et al. [3, 4, 23] and Tiwari et al. [10] and not repeated herein.

\subsection{Material constitutive models and properties}

Blast loading gives rise to high strain rates in any materials. Hence, strain rate dependent material constitutive models have been used for all the materials in the present investigations. Table 1 summarizes the physical properties, e.g. density $(\rho)$ and mechanical properties, e.g. Young's modulus $(E)$, Poisson's ratio ( $v)$, of all materials, the material constitutive models used in the present study, and the constitutive model parameters considered. Table 2 presents the dynamic increase factor (DIF) of the foam materials and sand under high rate loading.

Steel plates, stiffeners, and reinforcing bars in concrete slabs are modeled using the strain rate dependent, empirically developed Johnson-Cook (JC) model [26]. The strain rate dependent stressstrain response of the model is given by

$\sigma=\left(A+B \varepsilon^{n}\right)\left(1+C \log _{e} \varepsilon^{*}\right)\left(1-T^{* m}\right)$,

where $\varepsilon^{*}=\dot{\varepsilon} / \dot{\varepsilon}_{0}$ is the dimensionless plastic strain rate

Table 2 Dynamic increase factor (DIF) for different materials

\begin{tabular}{|c|c|c|c|c|c|}
\hline S. no. & $\begin{array}{l}\text { Material } \\
\text { description }\end{array}$ & $\begin{array}{l}\text { Material model (strain } \\
\text { rate dependent) }\end{array}$ & $\begin{array}{l}\text { Strain rate } \\
(\dot{\varepsilon})\left(\mathrm{s}^{-1}\right)\end{array}$ & $\begin{array}{l}\text { Dynamic increase } \\
\text { factor (DIF) }\end{array}$ & $\begin{array}{l}\text { References to model } \\
\text { parameters and } \\
\text { stress-strain curves }\end{array}$ \\
\hline 1. & Concrete & $\begin{array}{l}\text { Concrete damage } \\
\text { plasticity }\end{array}$ & 100 & $\begin{array}{l}1.5 \text { (compression) } \\
6 \text { (tension) }\end{array}$ & {$[28,30]$} \\
\hline 2. & Polyurethane & $\begin{array}{l}\text { Crushable foam } \\
\text { plasticity }\end{array}$ & $\begin{array}{r}950 \\
2,300\end{array}$ & $\begin{array}{l}4 \\
10\end{array}$ & {$[4,35,36]$} \\
\hline 3. & Dytherm & $\begin{array}{l}\text { Crushable foam } \\
\text { plasticity }\end{array}$ & $\begin{array}{r}950 \\
2,300\end{array}$ & $\begin{array}{l}4 \\
10\end{array}$ & [4] \\
\hline 4. & $\begin{array}{l}\text { Cenosphere aluminum alloy } \\
\text { syntactic foam } 90 \mu \mathrm{m}\end{array}$ & $\begin{array}{l}\text { Crushable foam } \\
\text { plasticity }\end{array}$ & $\begin{array}{r}1 \\
10 \\
750 \\
900 \\
1,400\end{array}$ & $\begin{array}{l}1.03 \\
1.11 \\
1.23 \\
1.22 \\
1.16\end{array}$ & [37] \\
\hline 5. & $\begin{array}{l}\text { Cenosphere aluminum alloy } \\
\text { syntactic foam } 200 \mu \mathrm{m}\end{array}$ & $\begin{array}{l}\text { Crushable foam } \\
\text { plasticity }\end{array}$ & $\begin{array}{r}1 \\
10 \\
750 \\
1,400\end{array}$ & $\begin{array}{l}1.63 \\
1.75 \\
1.95 \\
1.82\end{array}$ & [37] \\
\hline 6. & Sand & $\begin{array}{l}\text { Drucker-Prager } \\
\text { plasticity }\end{array}$ & $\begin{array}{l}100 \\
200\end{array}$ & $\begin{array}{l}1.37 \\
3\end{array}$ & {$[23,38]$} \\
\hline
\end{tabular}


at reference strain rate $\dot{\varepsilon}_{0}=1 \mathrm{~s}^{-1}, \dot{\varepsilon}$ is the equivalent plastic strain rate, and $T^{*}$ is the homologous temperature. Parameters $A, B, C, m$, and $n$ are the material constants. Here the expression in the first set of bracket gives the stress as a function of strain at $\varepsilon^{*}=1$ and $T^{*}=0$. The expressions in the second and third sets of brackets represent the effect of strain rate and temperature on stress, respectively. In the present study, Young's modulus, $E=210 \mathrm{GPa}$; Poisson's ratio, $v=0.3$; and density, $\rho=7,800 \mathrm{~kg} / \mathrm{m}^{3}$ are considered for steel. The constitutive model parameters $A, B, C$, and $n$, as described in Table 1 , are obtained from Goel et al. [3]. The effects of temperature are ignored in the present analyses.

The stress-strain responses of concrete and steel fiber reinforced concrete are simulated using the strain rate dependent concrete damage plasticity model. The concrete damage plasticity model is suitable for simulating the stress-strain and damage behavior of brittle materials [27]. The yield surface equation of concrete damage plasticity model is given by

$$
\begin{gathered}
F=\left(\sqrt{3 / 2} \sqrt{\bar{s}_{\mathrm{ij}}: \bar{s}_{\mathrm{ij}}}\right)-3 \alpha \bar{p}+\beta\left\langle\hat{\bar{\sigma}}_{\max }\right\rangle \\
-\gamma\left\langle-\hat{\bar{\sigma}}_{\max }\right\rangle-(1-\alpha) \bar{\sigma}_{c}=0
\end{gathered}
$$

where

$\alpha=\frac{\left(\sigma_{\mathrm{b} 0} / \sigma_{\mathrm{c} 0}\right)-1}{2\left(\sigma_{\mathrm{b} 0} / \sigma_{\mathrm{c} 0}\right)-1}$

$\beta=\frac{\bar{\sigma}_{\mathrm{c}}}{\bar{\sigma}_{\mathrm{t}}}(1-\alpha)-(1+\alpha)$

$\gamma=\frac{3\left(1-K_{\mathrm{c}}\right)}{2 K_{\mathrm{c}}-1}$

$\bar{\sigma}_{\mathrm{c}}=\frac{\sigma_{\mathrm{c}}}{\left(1-d_{\mathrm{t}}\right)}$

$\bar{\sigma}_{\mathrm{t}}=\frac{\sigma_{\mathrm{t}}}{\left(1-d_{\mathrm{t}}\right)}$

In Eqs. (2)-(7), all quantities under bar (“-”) represent the magnitude of the same quantities considering damage. Here, $\hat{\bar{\sigma}}_{\max }$ is the maximum principal effective stress; $\bar{s}_{\mathrm{ij}}$ is the deviatoric stress tensor; $\sigma_{\mathrm{b} 0}$ is the initial equibiaxial compressive yield stress; $\sigma_{\mathrm{c} 0}$ is the initial uniaxial compressive yield stress; $d_{\mathrm{t}}$ is the damage variable; and $K_{\mathrm{c}}$ is the ratio of the second deviatoric stress invariant on the tensile meridian to that on the compressive meridian at initial crushing for any given value of effective mean stress $\bar{p}\left[=\left(\bar{\sigma}_{1}+\bar{\sigma}_{2}+\bar{\sigma}_{3}\right) / 3\right]$. The Macaulay bracket \langle\rangle in Eq. (2) signifies that the quantities within the bracket take either positive or zero value. The model follows non-associated flow rule with the plastic potential surface $\left(G_{\mathrm{P}}\right)$, different from the yield surface $(F)$, given by

$G_{\mathrm{P}}=\sqrt{\left(\varepsilon \sigma_{\mathrm{t} 0} \tan \psi\right)^{2}+\left(\frac{3}{2} \bar{s}_{\mathrm{ij}}: \bar{s}_{\mathrm{ij}}\right)}-\bar{p} \tan \psi$

where $\psi$ is the dilation angle measured in the mean stress-deviatoric stress plane; $\sigma_{\mathrm{t} 0}$ is the uniaxial tensile stress at failure; and $\varepsilon$ is the eccentricity parameter. The compressive and tensile stress-strain curves of concrete at different strain rates and the evolution of damage with strain are obtained from the literature and added in the model as input.

The concrete damage plasticity model has been used to simulate the stress-strain response of concrete both in the PC and the RC slabs. Figure $2 \mathrm{a}$ shows the concrete compressive stress-strain curves under rate-independent and strain rate dependent loading obtained from [28]. The strain rate dependent tensile stress-strain curves of concrete have been computed using [21, 29]. For both PC and RC, Young's modulus, $E=25 \mathrm{GPa}$; Poisson's ratio, $v=0.2 ; \quad$ density, $\rho=2,643 \mathrm{~kg} / \mathrm{m}^{3} ; \quad$ dilatancy angle, $\psi=36^{\circ} ;$ compression yield strength, $\sigma_{\mathrm{c}, \text { yield }}=12.5 \mathrm{MPa} ;$ and tensile yield strength, $\sigma_{\text {t,yield }}=3.5 \mathrm{MPa}$ are considered. The DIF values of concrete have been calculated from [28, 30, 31] and presented in Table 2. The SFRC without minimum reinforcement is modeled as an equivalent continuum in the present study using the strain rate dependent concrete damage plasticity model. The physical and mechanical properties of SFRC are obtained from the parameters reported by [22, 32, 33]. The material properties are given in Table 1 for SFRC with $3 \%$ steel fiber by volume. For SFRC the material properties considered include: Young's modulus, $E=34.6 \mathrm{GPa}$; Poisson's ratio, $v=0.2$; density, $\rho=2,880 \mathrm{~kg} / \mathrm{m}^{3}$; dilatancy angle, $\psi=36^{\circ}$; compression yield strength, $\sigma_{\mathrm{c} \text {,yield }}=14 \mathrm{MPa}$; and tensile yield strength, $\sigma_{\mathrm{t} \text {,yield }}=4 \mathrm{MPa}$. The density of the SFRC has been calculated from the density of the PC considering the addition of $3 \%$ steel fiber by 

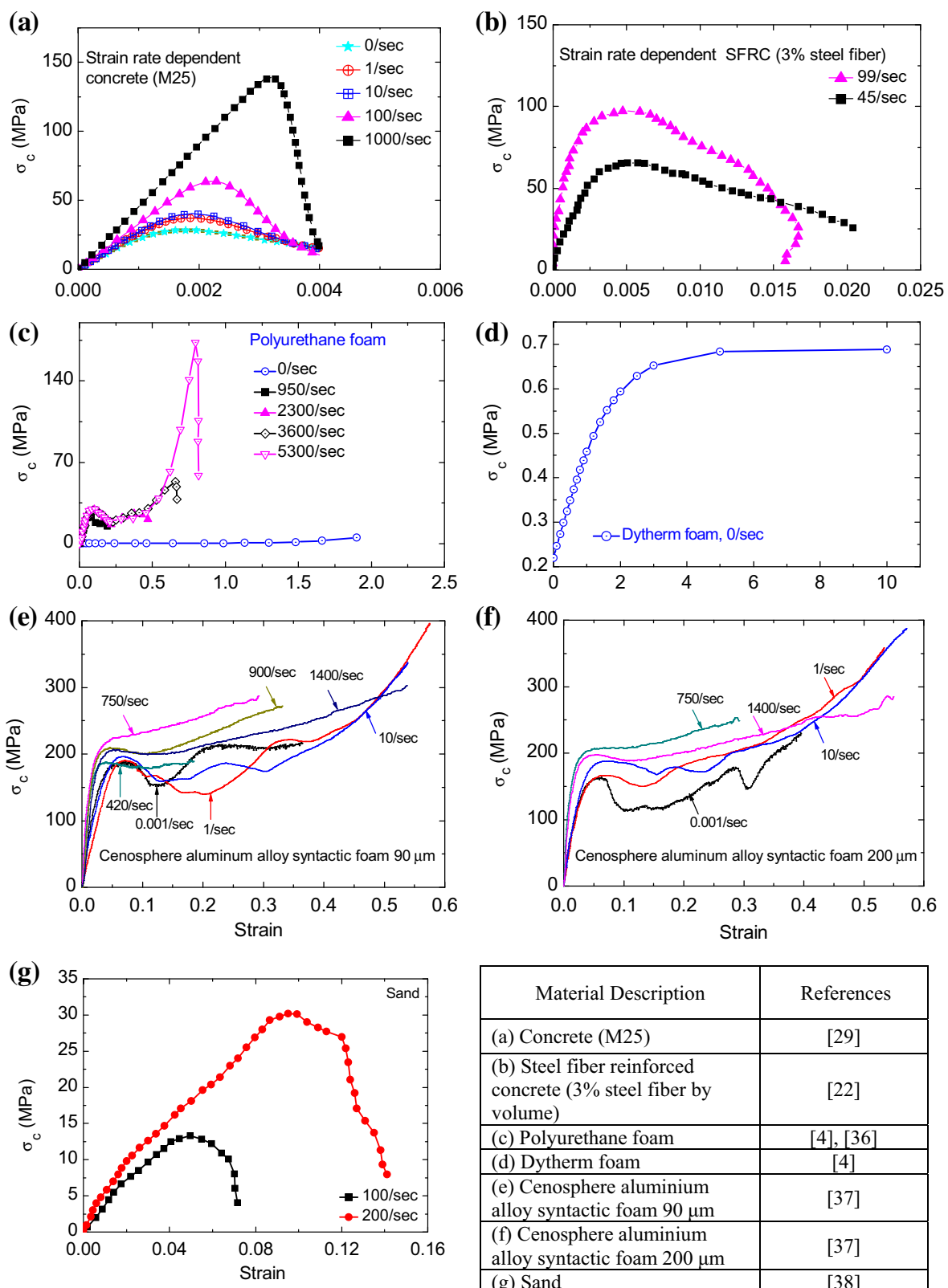

\begin{tabular}{|l|c|}
\hline \multicolumn{1}{|c|}{ Material Description } & References \\
\hline (a) Concrete (M25) & {$[29]$} \\
\hline $\begin{array}{l}\text { (b) Steel fiber reinforced } \\
\text { concrete }(3 \% \text { steel fiber by } \\
\text { volume) }\end{array}$ & {$[22]$} \\
\hline (c) Polyurethane foam & {$[4],[36]$} \\
\hline (d) Dytherm foam & {$[4]$} \\
\hline $\begin{array}{l}\text { (e) Cenosphere aluminium } \\
\text { alloy syntactic foam } 90 \mu \mathrm{m}\end{array}$ & {$[37]$} \\
\hline $\begin{array}{l}\text { (f) Cenosphere aluminium } \\
\text { alloy syntactic foam } 200 \mu \mathrm{m}\end{array}$ & {$[37]$} \\
\hline (g) Sand & {$[38]$} \\
\hline
\end{tabular}

Fig. 2 Material stress-strain response

volume. The yield strength of SFRC and the strain rate dependent compressive stress-strain curves of the SFRC are obtained from [22] and shown in Fig. 2b. The rate dependent stress-strain response at different strain rates has been computed herein using the DIF obtained from [30] which is same as concrete in this case.
The crushable foam plasticity model is used for all the foam materials. The constitutive model can simulate compressive stress induced compaction behavior of the foam materials [34]. The yield surface of the model takes an elliptical shape in the mean stress $(p)$ versus deviatoric stress $(q)$ plane. Inside the yield surface, the behavior of the foams remains linear 
elastic. The elliptical yield surface equation of the model is given by

$F=\sqrt{q^{2}+\alpha^{2}\left(p-p_{0}\right)^{2}}-B=0$

where $p_{0}$ is given by $\left(p_{\mathrm{c}}-p_{\mathrm{t}}\right) / 2 ; p_{\mathrm{c}}$ and $p_{\mathrm{t}}$ are the yield strength values of the foam material under hydrostatic compression and tension, respectively. The parameter $B$ is the magnitude of the intercept of the yield surface with the vertical axis for deviatoric stress, $q$; and the parameter $\alpha$ defines the shape of the yield surface in the meridional plane. The volumetric hardening of the model is defined by providing the experimental data for uniaxial compressive strength with axial strain. The strain rate dependence of the foam materials is included in the model by defining the dynamic increase factor (DIF) with the increase in strain rate. The constitutive model uses a non-associated flow rule with the plastic potential surface $\left(G_{\mathrm{P}}\right)$, given by

$G_{\mathrm{P}}=\sqrt{q^{2}+\frac{9}{2} p^{2}}$

The polyurethane, dytherm, and cenosphere aluminum alloy syntactic foam are modeled using the strain rate dependent crushing foam constitutive model. The physical properties of the foams and yield strength in compression are given in Table 1. The stress-strain curves for the polyurethane and dytherm foams are obtained as reported by Goel et al. [4], Song and Chen [35], and Bryson [36]. The strain rate dependent stressstrain curves for the cenosphere aluminum alloy syntactic foams are obtained from Goel et al. [37]. Figure 2c through $2 \mathrm{f}$ show the strain rate dependent stress-strain curves for the polyurethane, dytherm, and cenosphere aluminum alloy syntactic foams. The DIF parameters presented in Table 2 are calculated in the present study from the strain rate dependent stress-strain curves.

Sand is modeled using the Drucker-Prager material model as an equivalent continuum. The yield surface equation of Drucker-Prager model is given by

$F=t-p^{\prime} \tan \beta-d=0$

where

$t=\frac{q}{2}\left[1+\frac{1}{K}-\left(1-\frac{1}{K}\right)\left(\frac{r}{q}\right)^{3}\right]$

where $q$ is the deviatoric stress $\left(\sqrt{3 / 2} \sqrt{s_{\mathrm{ij}}: s_{\mathrm{ij}}}\right), s_{\mathrm{ij}}$ is the deviatoric stress tensor, $p^{\prime}$ is the mean effective stress, $r$ is the third invariant of the deviatoric stress tensor; and $K$ is a scalar parameter that determines the shape of the yield surface and maintains the convexity of the yield surface in the deviatoric $(\pi)$ plane. The parameter $\beta$ is the slope of linear Drucker-Prager yield surface in the $p^{\prime}-t$ plane. The correlation between the parameter $\beta$ with the angle of internal friction, $\phi$, in the more conventional normal stress $\left(\sigma^{\prime}\right)$ - shear stress $(\tau)$ plane is at the stage of zero dilatancy (the critical state of sand) is given by

$\tan \beta=\frac{\sqrt{3} \sin \phi}{\sqrt{1+(1 / 3) \sin ^{2} \phi}}$

The hardening parameter $d$ in the $p^{\prime}-t$ plane is related to cohesion (c) in the $\sigma^{\prime}-\tau$ plane through the following correlation given by

$\frac{d}{c}=\frac{\sqrt{3} \cos \phi}{\sqrt{1+(1 / 3) \sin ^{2} \phi}}$

For sands, the cohesion $(c)$ is considered to be zero. The plastic potential surface $\left(G_{\mathrm{P}}\right)$ of the model is given by

$G_{\mathrm{P}}=\frac{q}{2}\left[1+\frac{1}{K}-\left(1-\frac{1}{K}\right)\left(\frac{r}{q}\right)^{3}\right]-p^{\prime} \tan \psi_{\mathrm{tp}}$

where the correlation between $\psi_{\text {tp }}$ in the $p^{\prime}-t$ plane and the dilatancy angle $(\psi)$ in the $\sigma^{\prime}-\tau$ plane of sand is given by

$\tan \psi_{\mathrm{tp}}=\frac{\sqrt{3} \sin \psi}{\sqrt{1+(1 / 3) \sin ^{2} \psi}}$

The Eqs. (13), (14) and (16) are obtained by comparing the Drucker-Prager model parameters defined in $p^{\prime}-t$ plane with the Mohr-Coulomb model parameters defined in $\sigma^{\prime}-\tau$ plane. A nonassociated flow rule is considered in the present analysis by considering the dilatancy angle of sand to be different from the friction angle.

Sand is modeled with Young's modulus, $E=50 \mathrm{MPa}$; Poisson's ratio, $v=0.2$; and density, $\rho=1,800 \mathrm{~kg} / \mathrm{m}^{3}$. The yield strength of sand, $\sigma_{\text {c,yield }}=0.1 \mathrm{MPa}$, friction angle, $\phi=30^{\circ}$ and dilatancy angle, $\psi=10^{\circ}$ are assumed. The strain rate dependent stress-strain curves for sand are obtained from [38] as shown in Fig. 2g. The DIF values are 
Fig. 3 Pressure-time blast load profile

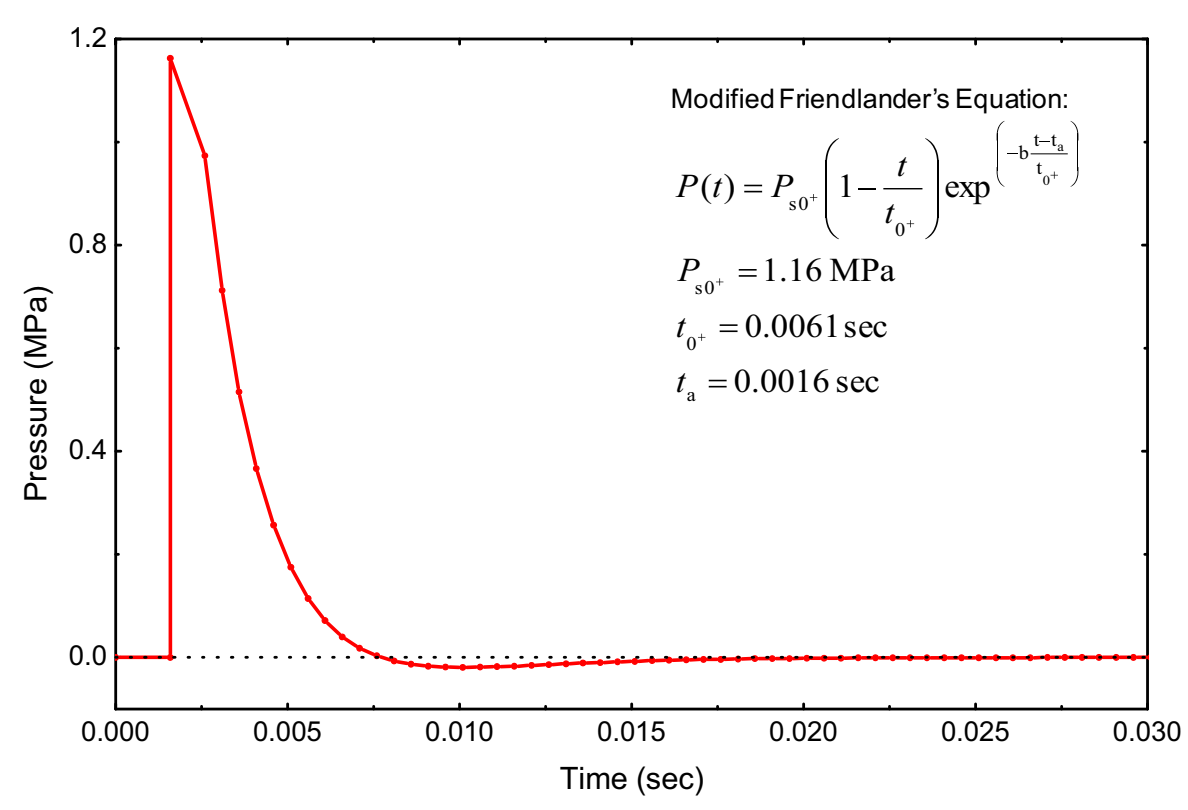

Fig. 4 Central node displacement time histories for PC, RC, and SFRC slabs
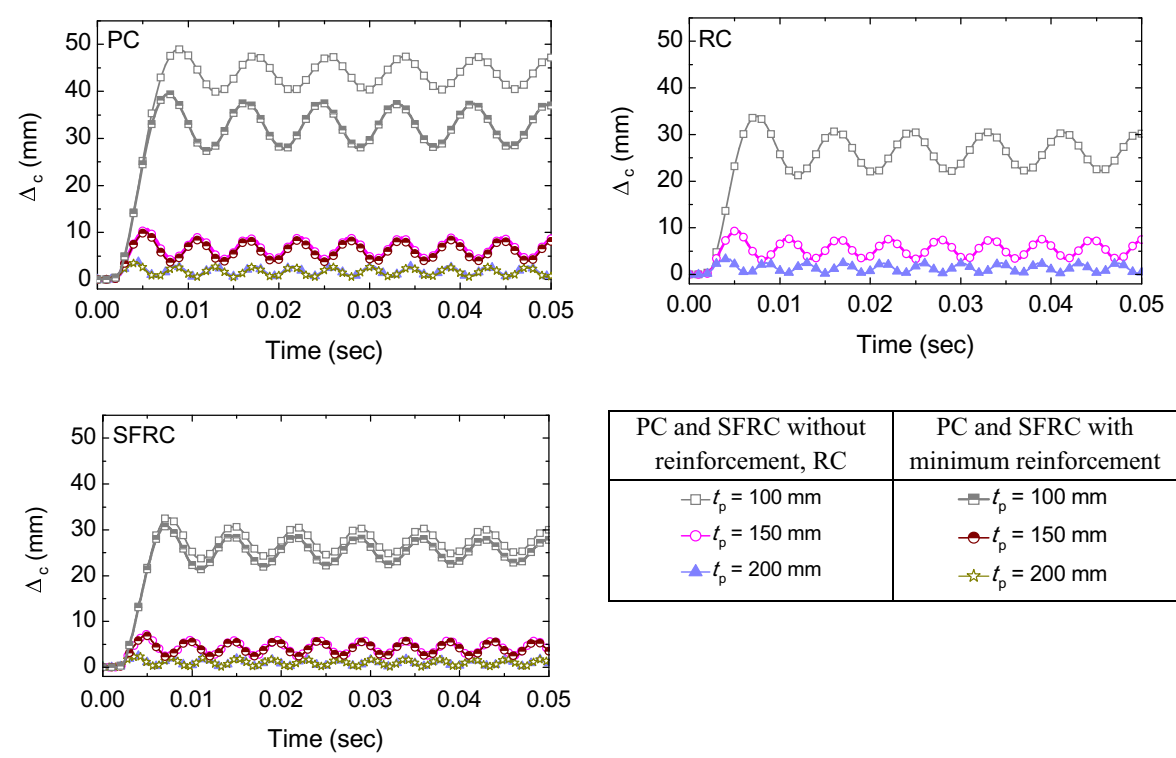

calculated from the stress-strain curves as given in Table 2.

\subsection{Calculation of blast load}

Blast load is applied in the present study as pressure time history curves on the plates, slabs and panels. All analyses have been performed for peak positive blast overpressure of $1.16 \mathrm{MPa}$ applied for $6.1 \mathrm{~ms}$ as obtained from TM5-1300 US army manual [39]. The blast pressure time history curve is shown in Fig. 3. The exponential decay in the blast pressure and the negative blast pressure are calculated using the modified Friedlander's equation [3]. In the modified Friedlander's equation, shown in Fig. 3, $P(0)$ is ambient atmospheric pressure; $P_{\mathrm{s} 0^{+}}$is peak overpressure in $\mathrm{MPa} ; t_{\mathrm{a}}$ is arrival time in $\mathrm{ms} ; t_{0^{+}}$is positive pressure wave duration in $\mathrm{ms}$; and $b$ is dimensionless wave decay coefficient 
Fig. 5 a Central node displacement time history for stiffened and unstiffened steel plates. b Displacement (in $\mathrm{m}$ ) contour in the loading direction, deformed shape and plastic strain contours in the unstiffened steel plate
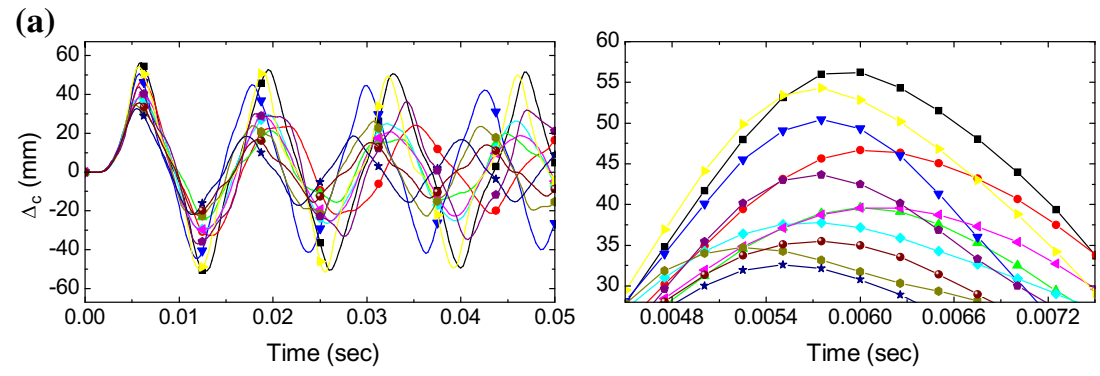

$-P_{1}$

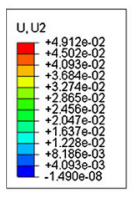

L.
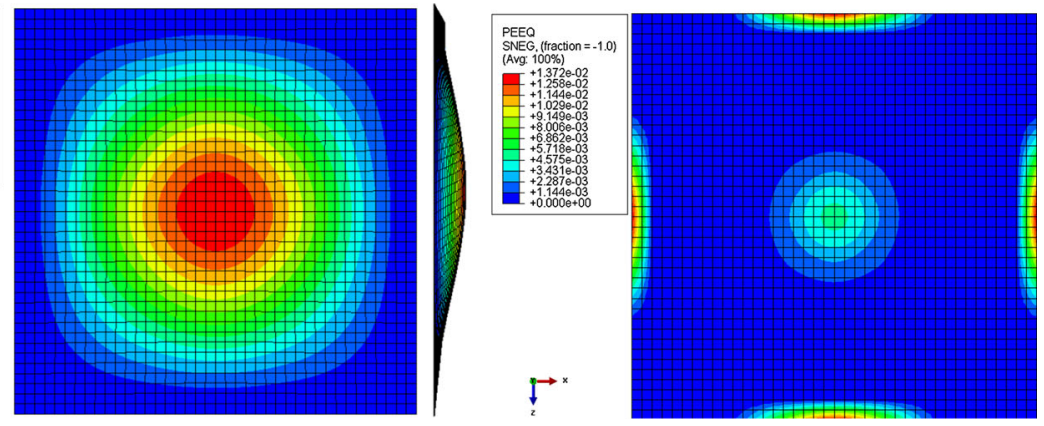
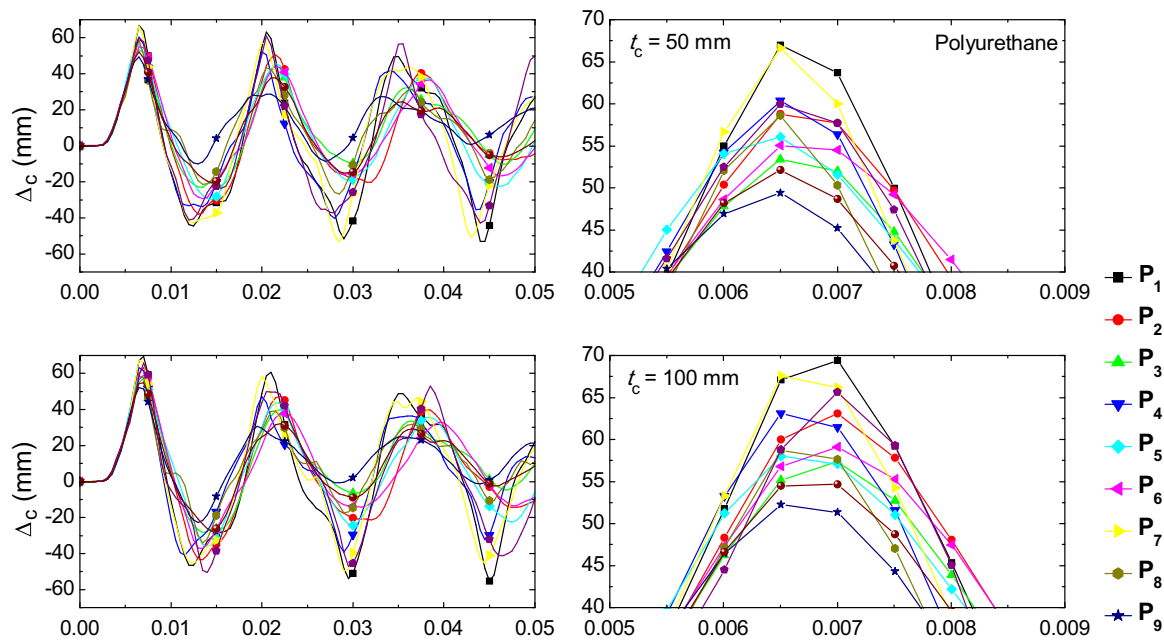

$P^{2}$

$-P_{3}$

$\rightarrow \mathrm{P}_{4}$

$\rightarrow P_{5}$

$4 P_{6}$

$P_{7}$

$\rightarrow P_{8}$

$\star P_{9}$
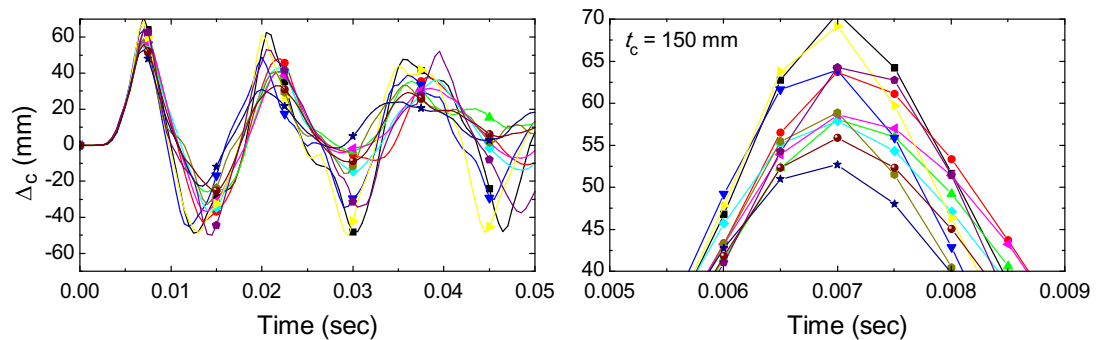

$P_{11}$

Fig. 6 Central node displacement time history of the SPS composite sandwich panel 
Fig. 7 Central node displacement time history of the SDS composite sandwich panel
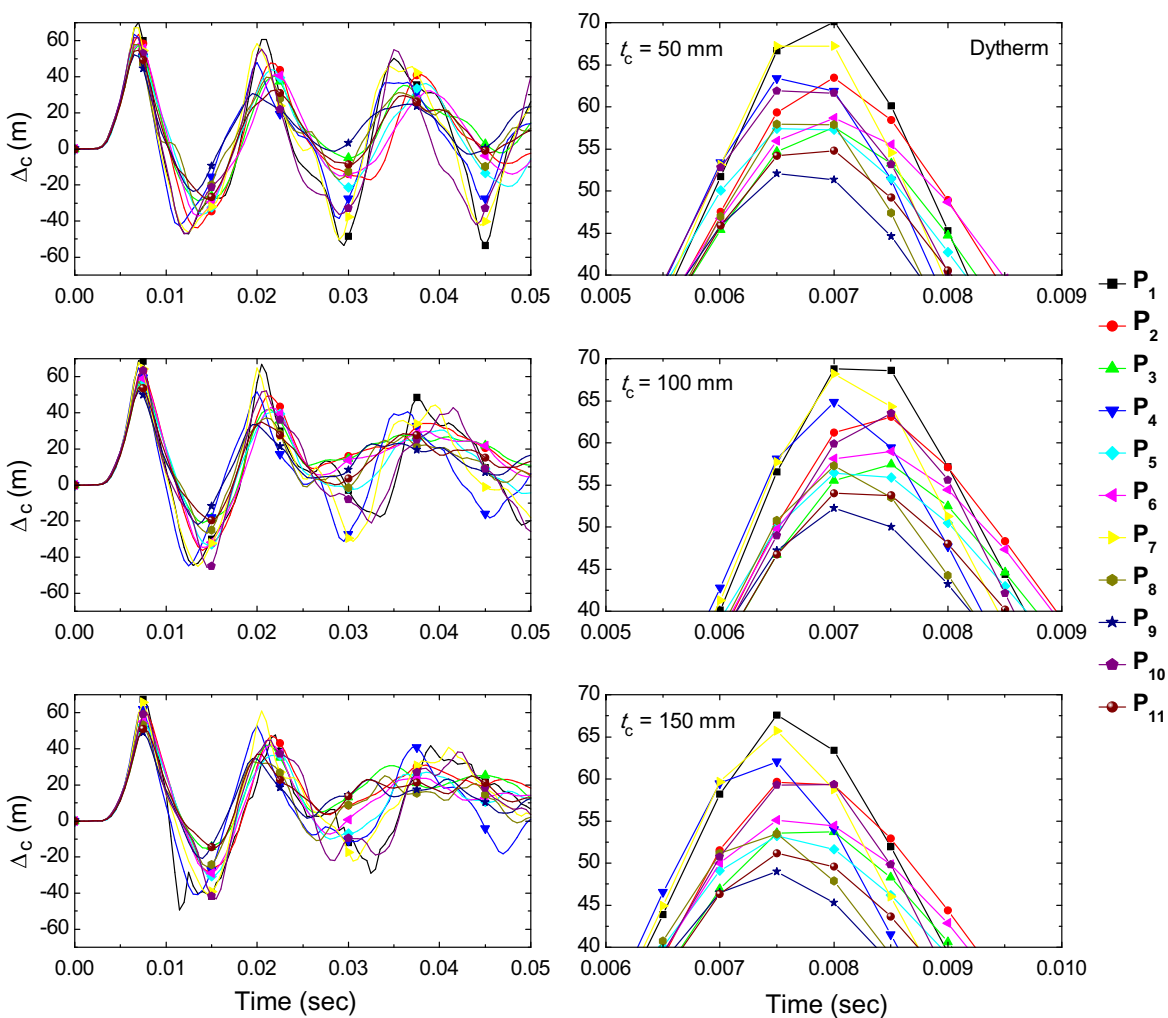

expressed as $\log _{\mathrm{e}}\left(b\left|P_{\mathrm{s}^{-}} / P_{\mathrm{s}^{+}}\right|\right)+b+1=0$. Here $P_{\mathrm{s} 0^{-}}$denotes negative pressure expressed in $\mathrm{MPa}$. The finite element analyses are performed using Abaqus 6.11 with explicit central difference numerical integration algorithm. An automatic time increment estimator with global stable increment without any time scaling factor is used in the analyses. It may be noted that different hydrocodes are available for blast analysis of structures, e.g. Abaqus, Ansys, LS-Dyna, AutoDyn to name a few. However, for a specific blast pressure time history, the structural response obtained from different hydrocodes remains comparable. Comparative studies on different hydrocodes in blast simulation have been reported in [40-46].

\section{Finite element simulation results and discussions}

Numerical analyses carried out in the present study aims to compare the performance of panels built of stiffened and unstiffened steel plates, plain concrete, reinforced concrete, and steel fiber reinforced concrete slabs and stiffened and unstiffened composite sandwich panels (SPS, SDS, SAS90, SAS200, and SSS) under blast loading. The performance against blast loading is quantified using peak central point displacement $\left(\Delta_{c}\right)$ of the plates, slabs, and panels.

Figure 4 shows the displacement time history plots for 100, 150, and $200 \mathrm{~mm}$ thick PC, RC, and SFRC slabs. The PC slabs without any reinforcement show maximum displacement under the blast loading followed by RC and SFRC slabs. Moreover, the PC and RC slabs with different DIF values of concrete show comparable displacement. The displacement time history curve for $100 \mathrm{~mm}$ thick PC slab reaches $48.9 \mathrm{~mm}$ and oscillates at the value. No reduction in the displacement after peak load signifies the damage of the PC slabs under blast loading. The PC slab with minimum reinforcement exhibits lesser displacement as compared to the PC slab without any reinforcement for $100 \mathrm{~mm}$ thick slabs. The displacements become comparable for 150 and $200 \mathrm{~mm}$ thick slabs with and without minimum reinforcement. For the RC and SFRC slabs, the displacement time histories oscillate at much lower value of the displacement than that for the PC slab. For $100 \mathrm{~mm}$ thick SFRC slab, the peak displacement is $32.6 \mathrm{~mm}$. The SFRC slabs with minimum reinforcement show lesser displacement as 
Fig. 8 Central node displacement time history of the SAS 90 composite sandwich panel
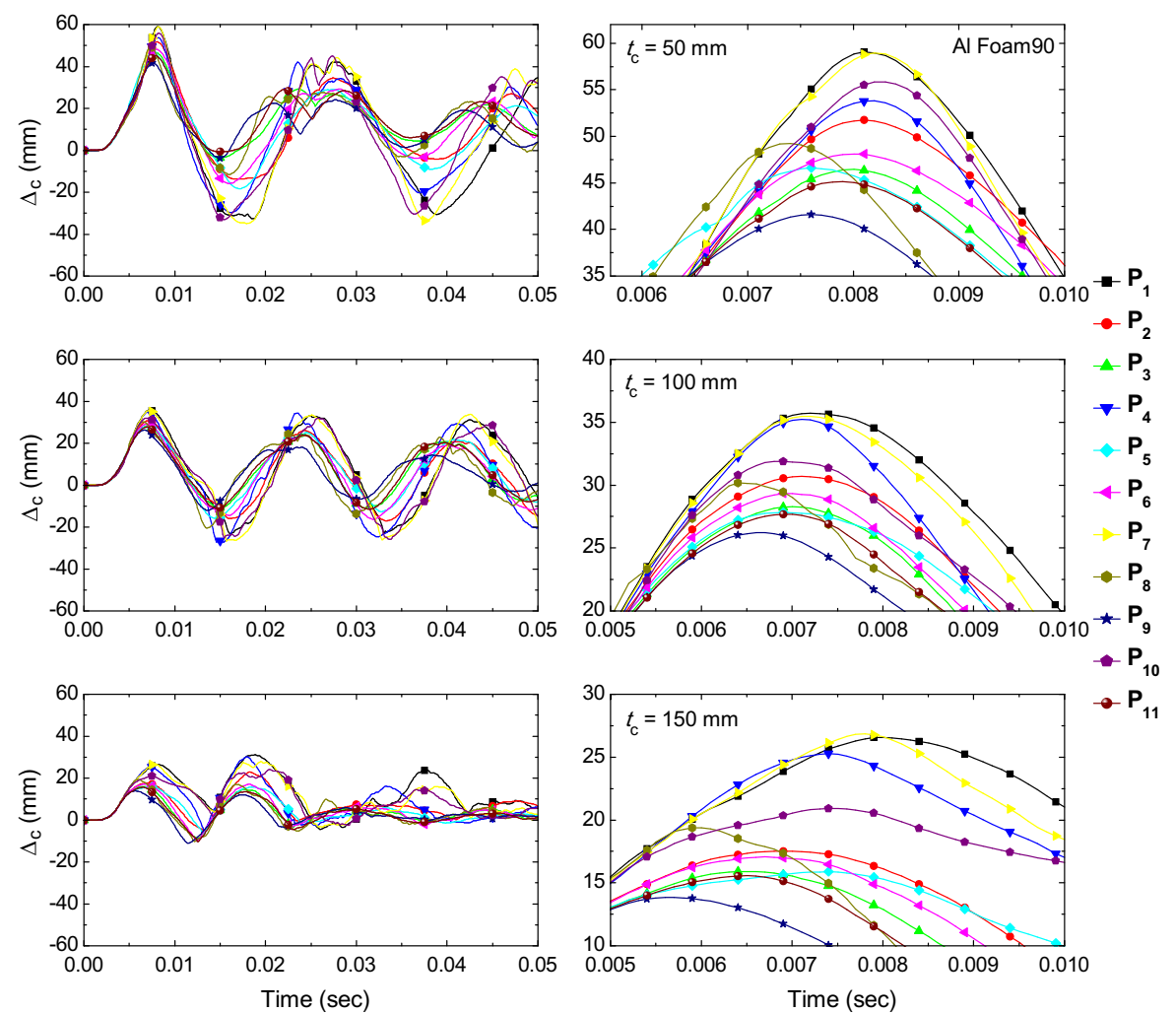

compared to that without any reinforcement for $100 \mathrm{~mm}$ thick slabs. The displacements become comparable for 150 and $200 \mathrm{~mm}$ thick slabs with and without minimum reinforcement.

The SFRC slabs exhibit lesser peak displacement as compared to the PC and RC slabs for all thicknesses. The higher displacement in the PC slab as compared to the RC and SFRC slabs is due to the absence of reinforcement in the PC slabs. The lower displacement in the SFRC slabs may be attributed to the higher strength, stiffness, and mass density of these slabs as compared to the PC and RC slabs. The absence of oscillations in the displacement of RC and PC slabs is due to the damage of these slabs under the blast loading. The higher amount of oscillations in the displacement time history for the SFRC slabs may be attributed to the lesser damage of these slabs.

Figure 5a shows the displacement $\left(\Delta_{c}\right)$ time history plots for the central node of the unstiffened $\left(\mathrm{P}_{1}\right)$ and the stiffened $\left(\mathrm{P}_{2}\right.$ to $\left.\mathrm{P}_{11}\right)$ steel plates. The displacement time history plots for all stiffener configurations show similar trend. However, the stiffened steel plates show lower displacement as compared to the unstiffened plate under the same blast loading. For the unstiffened steel plate, a maximum of $56.3 \mathrm{~mm}$ peak displacement is observed. Figure $5 \mathrm{~b}$ shows a typical displacement contour plot in the loading direction and side-view of deformed shape for the unstiffened steel plate. The plastic strain contours in the unstiffened steel plate are also presented in Fig. 5b. High value of plastic strain is observed in the unstiffened plate. Among the stiffened steel plates, minimum peak displacement is observed in $\mathrm{P}_{9}$ as $32.6 \mathrm{~mm}$ followed by $\mathrm{P}_{8}$ and $\mathrm{P}_{11}$ showing 34.7 and $35.5 \mathrm{~mm}$ peak displacements, respectively. The minimum peak displacement in $\mathrm{P}_{9}$ stiffened steel plate may be attributed to the placement of the stiffener which passes through the central node of the plate. The higher peak displacement in $\mathrm{P}_{11}$ as compared to $\mathrm{P}_{9}$ proves that it is the orientation of the stiffeners and not the total weight that governs the blast response mitigation. The circular stiffener configurations exhibit lower blast response reduction as compared to the rectangular or rhombic stiffener configurations.

Figures 6, 7, 8, 9 and 10 show the central node displacement time history plots for the back sheet of the SPS, SDS, SAS90, SAS200, and SSS composite sandwich panels respectively for 50, 100, and $150 \mathrm{~mm}$ foam/sand thicknesses. In the figures, similar trend in 
Fig. 9 Central node displacement time history of the SAS200 composite sandwich panel
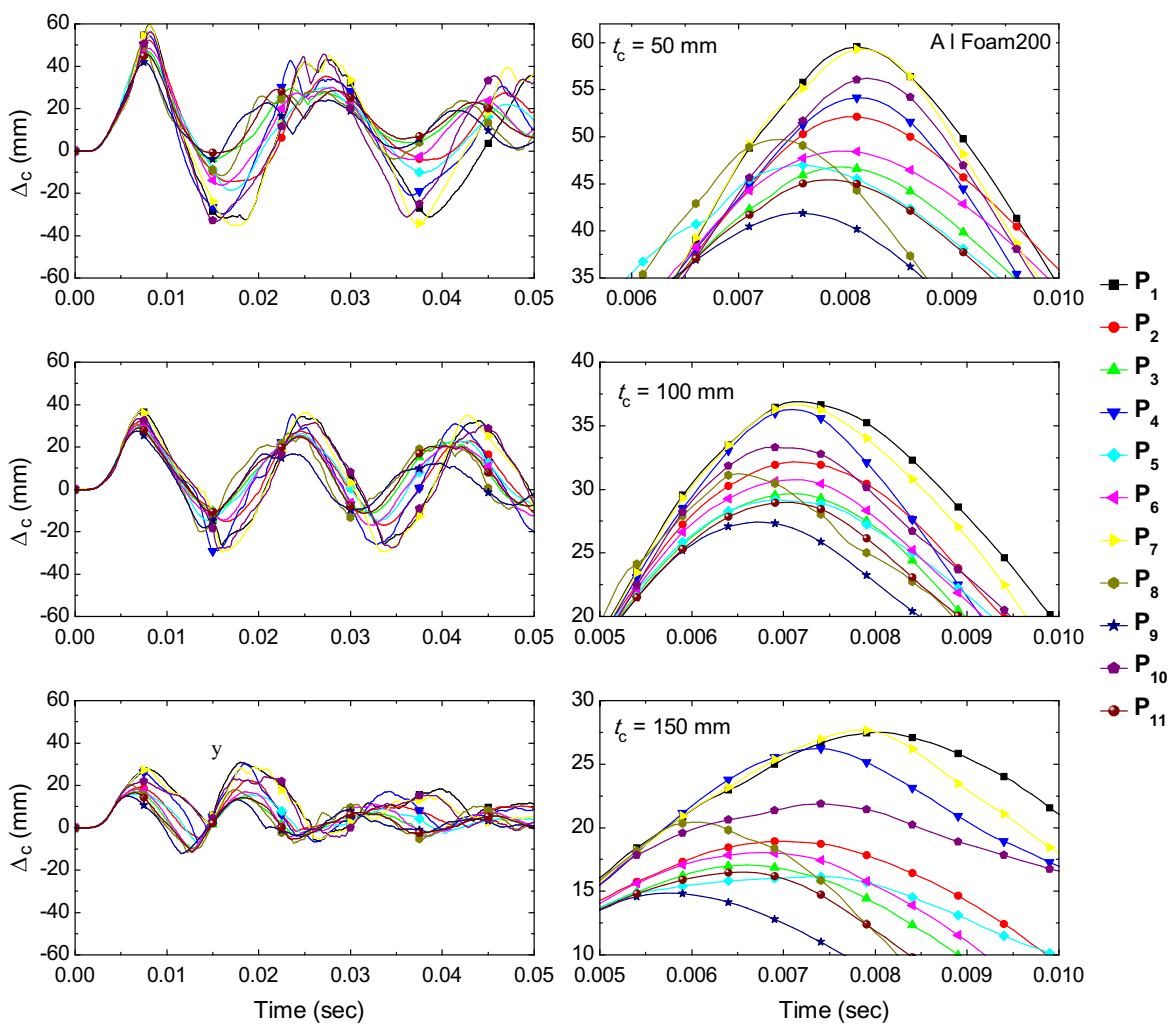

the displacement time histories is observed for stiffened plates and stiffened composite sandwich panels. The highest peak displacement is observed in the unstiffened panels; introduction of stiffener reduces the displacement. Similar to the steel plate analyses, the lowest peak displacement in the back sheet of the composite sandwich panels is observed in $\mathrm{P}_{9}$ stiffened plate followed by $\mathrm{P}_{8}$ and $\mathrm{P}_{11}$ stiffened panels. The peak displacement decreases with increasing foam and sand layer thicknesses except in the cases of SPS and SDS panels. The SPS and SDS panels exhibit severe damage under the blast loading; hence, inconsistent displacement pattern is observed in these panels. For the SPS panels with $150 \mathrm{~mm}$ core thicknesses, higher displacement is experienced as compared to the $50 \mathrm{~mm}$ thick core. Similarly, for the SDS panels with $100 \mathrm{~mm}$ core thicknesses, higher displacement is experienced as compared to the $50 \mathrm{~mm}$ core. However, the SDS panels with $150 \mathrm{~mm}$ thick core show lesser displacement as compared to both 50 and $100 \mathrm{~mm}$ thick cores which are reasonable. The peak central node displacements in the back sheet of the SDS and SSS panels with 50 and $100 \mathrm{~mm}$ thick foams and sand are higher than the peak central node displacement in steel plates of $20 \mathrm{~mm}$ thickness. However, for $150 \mathrm{~mm}$ thick foam layers, the central node displacement becomes lower than that observed in the steel plate. For the SAS90 and SAS200 panels, peak central node displacement of the back sheet under the blast loading is observed to be higher than the steel plate only in the case of $50 \mathrm{~mm}$ thick foam; however, for 100 and $150 \mathrm{~mm}$ thick foams, the peak central node displacement becomes smaller than that observed in the steel plates.

The decrease of displacement with increasing foam/sand core thickness of the composite sandwich panels is attributed to the higher blast energy absorption by the thicker cores and thus, lesser energy transfer to the back sheets. Higher displacement of polyurethane and dytherm foams and sand core composite sandwich panels as compared to the $20 \mathrm{~mm}$ thick steel plate is due to the lower stiffness and yield strength of these foams. Although the total thickness of the face and back sheets sums up to the steel plate thickness, the split positioning of the face and back sheets causes yielding of the thinner face sheet. Due to the yielding of the face sheet and the densification of the foam and sand, central node of the 
Fig. 10 Central node displacement time history of the SSS composite sandwich panel
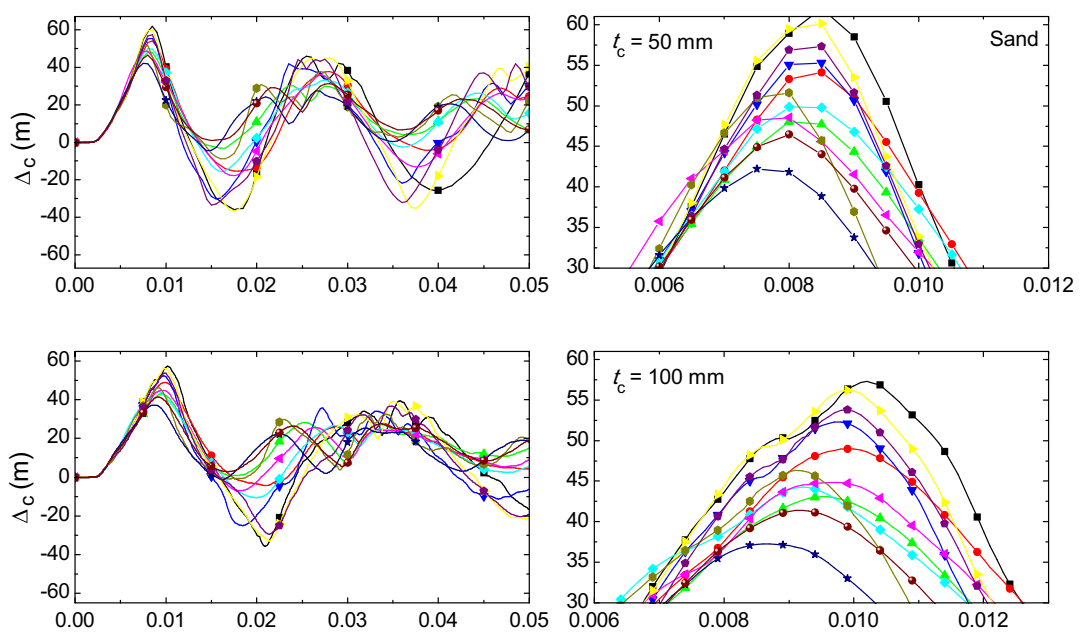

$-P_{1}$

$\rightarrow \mathrm{P}_{2}$

$\sim P_{3}$

$\rightarrow P_{4}$

$\rightarrow P_{5}$

$4 P_{6}$

$P_{7}$

$-P_{8}$

$\star P_{9}$

$\rightarrow P_{10}$
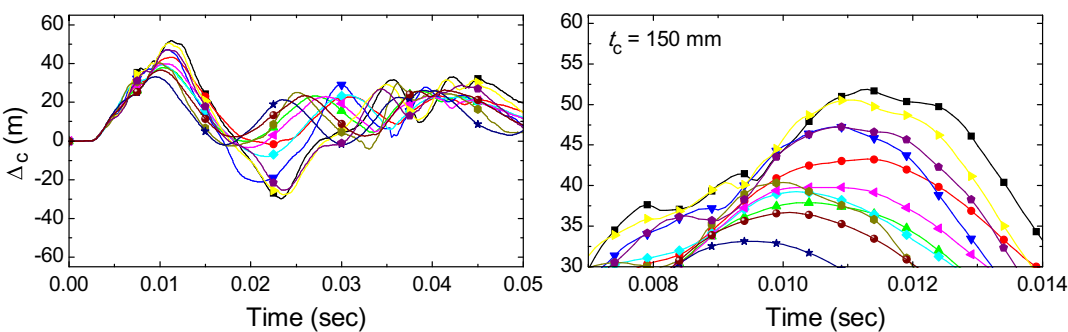

back sheet experiences more displacement as compared to the single steel plate with equal combined thickness. In the SAS90 and SAS200 foam panels, the foams have higher moduli of elasticity and yield strengths as compared to the polyurethane and dytherm foams and sand. This results in lower displacement of the back sheet in the SAS panels as compared to the SPS, SDS, and SSS panels. From these results, it may be concluded that not only the stiffener configurations that contributes to the blast response reduction but also the thickness and the type of the foam does significantly affect the blast response reduction.

It may be summarized from Figs. 4 through 10 that under the same blast loading, the SFRC slabs exhibits the lowest peak displacement followed by the RC and PC slabs. Steel plates show lower displacement than all the composite sandwich panels with $50 \mathrm{~mm}$ foam/ sand core, however, it shows higher displacement than the PC slabs. For the SDS and SSS composite sandwich panels, $150 \mathrm{~mm}$ thick foam/sand core show lower displacement than the steel plates. However, the SAS90 and SAS200 foam composite sandwich panels with 100 and $150 \mathrm{~mm}$ thick cores show lower displacement as compared to the steel plates. The panels with $\mathrm{P}_{9}$ stiffener configuration exhibit lowest displacement. Figure 11 shows the peak central node displacement for PC, RC, and SFRC slabs of different thicknesses and with minimum reinforcement, steel plate and composite sandwich panels with $\mathrm{P}_{9}$ stiffener configuration. The panel with $\mathrm{P}_{9}$ stiffener configuration experiences the lowest back sheet peak displacement among all the stiffener configurations. The SAS90 composite sandwich panel with 100 and $150 \mathrm{~mm}$ thick foam cores and $\mathrm{P}_{9}$ stiffener configuration, respectively show peak central node displacements of $26.2 \mathrm{~mm}$ and $13.8 \mathrm{~mm}$ which are $24.5 \%$ and $136.2 \%$ lesser than the displacement of steel plate with $\mathrm{P}_{9}$ stiffener configuration. The $200 \mathrm{~mm}$ thick SFRC slab shows the lowest peak displacement of $2.5 \mathrm{~mm}$. From these plots, it may be concluded that among the single layered slabs and plates, the SFRC slab is effective alternative as compared to the conventional RC and PC slabs and steel plates, keeping in mind the higher cost of steel. Among the composite sandwich panels, SAS90 and SAS200 foam-core composite sandwich panels are effective in blast response mitigation. The lightweight SDS 

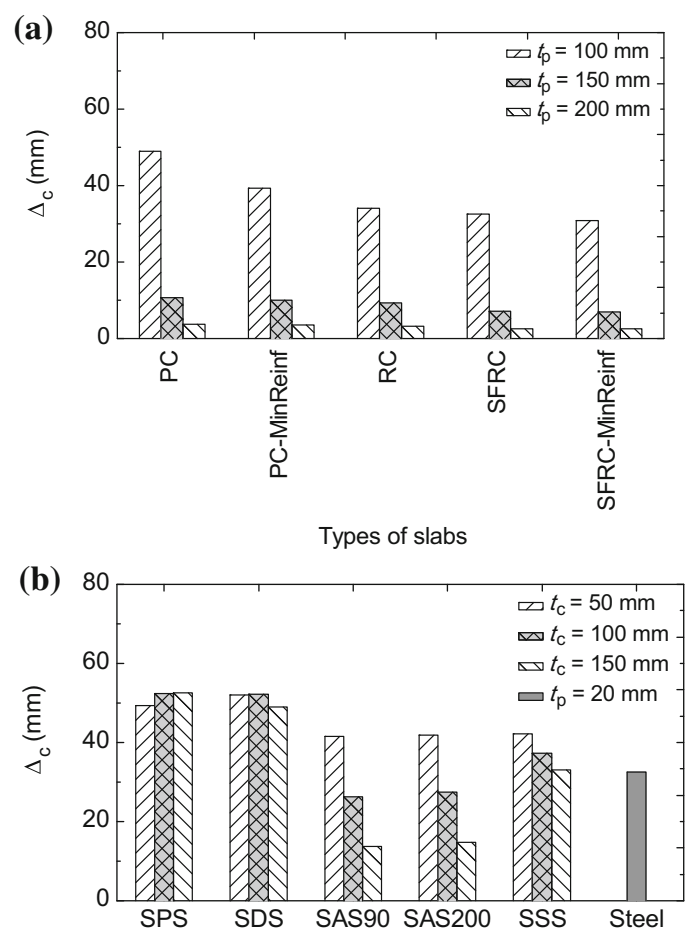

Types of $\mathrm{P}_{9}$ stiffened composite sandwich panels and steel plate

Fig. 11 Peak central node displacement for a slabs and $\mathbf{b} \mathrm{P}_{9}$ stiffened composite sandwich panels and steel plate

panel with $150 \mathrm{~mm}$ thick foam may also be used effectively in blast response reduction although with comparatively lesser response reduction capabilities. The light weight of these materials may prove to be advantageous as compared to the SFRC slabs. Steel, although shows excellent blast resistant capability, may be a costlier option in blast response mitigation comparatively. The choice of suitable material in a given application for enhancing blast resistance capabilities can thus be made based on the comparative performance shown here.

In addition to the displacement, energy studies of selected cases have also been carried out in the present study to gain insight in the mitigation of blast response. The total energy in blast loading gets converted to strain energy (S.E.) and kinetic energy (K.E.). The strain energy dissipates through inelastic deformation and damage or remains stored in the elastic regions of the models. Figure 12 shows the strain energy and the kinetic energy time history plots for the PC, RC, and SFRC slabs. From the energy plots, it is observed that the strain energy reaches peak when the models exhibit peak displacement. After the peak displacement, the models vibrate freely which results in increase in the kinetic energy. The strain energy and kinetic energy decrease with increasing thickness of slabs due to reduced damage. For the SFRC slabs, lower strain energy and kinetic energy are observed as compared to the PC and RC slabs due to lower displacement and lesser damage of these slabs under the blast loading. The strain and kinetic energy of the PC and SFRC slabs with minimum reinforcement are comparable with that of the slabs without reinforcement.

Figure 13 shows comparison of the cumulative strain energy and kinetic energy in all composite sandwich panel cores of same thicknesses at the end of $0.05 \mathrm{~s}$ which is the total blast load analysis run time. For the SPS, SDS, and SSS composite sandwich panels, maximum cumulative energy response is observed in $150 \mathrm{~mm}$ foam/sand cores followed by 100 and $50 \mathrm{~mm}$ thick cores. However, the energy response of the AlFoam 90 and AlFoam 200 cores in the SAS90 and SAS200 panels show different trend. For the AlFoam90 core of the SAS90 panel, maximum cumulative strain energy is observed in the $100 \mathrm{~mm}$ thick foam followed by 150 and $50 \mathrm{~mm}$ thick cores. Similar cumulative strain energy response is observed in the AlFoam 200 core of the SAS200 foam panel. The cumulative kinetic energy of the $100 \mathrm{~mm}$ thick AlFoam90 core in the SAS90 panel is observed to be the maximum followed by 50 and $150 \mathrm{~mm}$ thick cores. For the SAS200 panel, cumulative kinetic energy of $50 \mathrm{~mm}$ thick AlFoam 200 core is maximum followed by $100 \mathrm{~mm}$ and $150 \mathrm{~mm}$ thick cores. The $50 \mathrm{~mm}$ thick core exhibits more oscillation and thus higher cumulative kinetic energy. The $100 \mathrm{~mm}$ thick core shows higher strain energy and medium kinetic energy due to partial damage of the core. Lesser strain energy and kinetic energy in $150 \mathrm{~mm}$ thick cores may be attributed to lesser damage of these cores under the blast loading.

\section{Insights into design}

A task committee on blast-resistant design of buildings in American petrochemical facilities has specified that the blast response of structural components is governed by the ductility ratio $(\mu)$ and support rotation $(\theta)$ of the component [47]. Ductility ratio is expressed as the ratio of maximum component deflection $\left(X_{\mathrm{m}}\right)$ 
Fig. 12 Strain and kinetic energy time histories for PC, $\mathrm{RC}$, and SFRC slabs
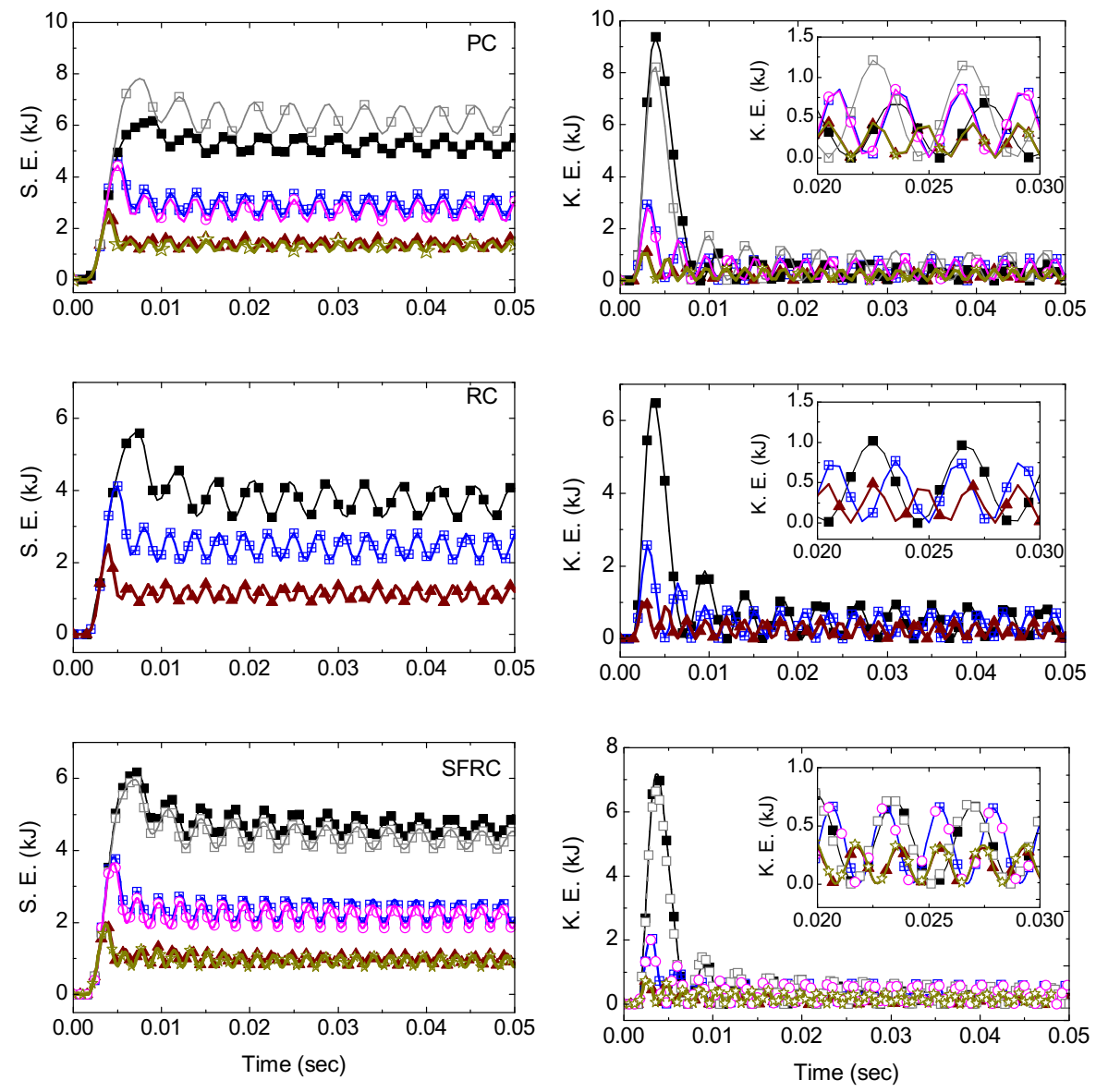

Without reinforcement (PC and SFRC) and RC

With minimum reinforcement (PC and SFRC)

$$
\begin{aligned}
\rightarrow-t_{\mathrm{c}} & =100 \mathrm{~mm} \\
-t_{\mathrm{c}} & =150 \mathrm{~mm} \\
-t_{\mathrm{c}} & =200 \mathrm{~mm}
\end{aligned}
$$

$-\square-t_{\mathrm{c}}=100 \mathrm{~mm}$

$-0-t_{\mathrm{c}}=150 \mathrm{~mm}$

$\therefore-t_{\mathrm{c}}=200 \mathrm{~mm}$

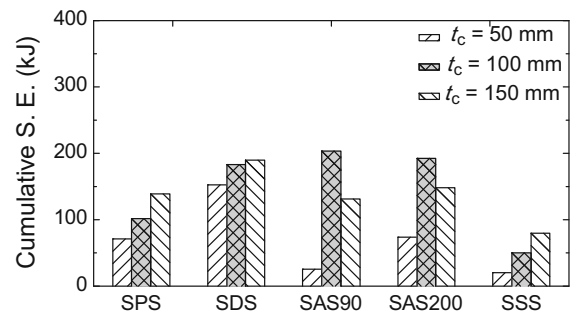

Types of $P_{9}$ stiffened composite sandwich panels

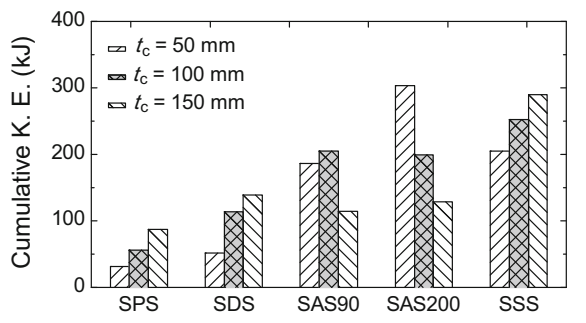

Types of $\mathrm{P}_{9}$ stiffened composite sandwich panels

Fig. 13 Cumulative strain and kinetic energy at the end of analysis for the core of $\mathrm{P}_{9}$ stiffened composite sandwich panels

under a particular blast scenario to the yield deflection $\left(X_{\mathrm{y}}\right)$ of the component. The yield deflection is governed by the type of the structure, i.e., whether the structure or the component is determinate or indeterminate in nature. The ductility ratio $(\mu)$ is related to the plastic strain in the structural component, 
and it is assumed that structural failure occurs when the plastic strain approaches the material failure strain. In blast resistant design, the dynamic response, e.g. ductility and support rotation of the structural component, which also indirectly accounts for the tolerable level of damage, is measured and compared against the specified deflection criteria [30, 47]. For the sandwich and the non-composite panels considered in the present work, the maximum deflection values may be obtained directly from the numerical analysis results and subsequently the ductility ratio and support rotation values may be calculated.

It may also be noted that the materials used for structural construction also render significant impact in blast resistant design of the structural components. It has been mentioned in the literature that lightweight advanced materials such as foams (metal and polymeric foams) may exhibit higher potential for their application in blast mitigation in the form of sacrificial blast walls [48, 49] as compared to steel and concrete. This has also been proved through the numerical analyses carried out in the present work that the sandwich panels with cenosphere aluminum alloy syntactic foam exhibit lower displacement under blast loading as compared to concrete and steel panels. The lightweight flexible type foam results in reduction of energy transfer to the parent structure, thus helping in blast mitigation in comparison with the rigid protection system and may be used in blast resistant design.

\section{Conclusions}

Comparative performance of panels built of steel plates, concrete slabs and composite sandwich panels with foam and sand cores under blast loading has been investigated. For steel plates and composite sandwich panels, both stiffened and unstiffened options have been used. Concrete slabs have been modeled with and without reinforcement. The effect of stiffener configuration, thicknesses of slabs, and thicknesses of foam and sand cores has been investigated. The following conclusions are drawn from this investigation:

1. Steel plates exhibit higher displacement as compared to concrete and composite sandwich panels. Stiffened steel plates exhibit lesser displacement as compared to unstiffened steel plates. The plates for which the stiffener passes through the central node of the plate exhibit higher blast response reduction capability. The circular stiffener configurations exhibit lower blast response reduction as compared to the rectangular or rhombic stiffener configurations.

2. Steel fiber reinforced concrete slabs exhibit lesser displacement, lesser damage, and higher energy dissipation as compared to the plain and reinforced concrete slabs. Hence, steel fiber reinforced concrete may be effectively used in blast response reduction.

3. Comparison among the composite sandwich panels with polyurethane, dytherm, and cenosphere aluminum alloy syntactic foams with the average sizes of cenosphere 90 and $200 \mu \mathrm{m}$ show that cenosphere aluminum alloy syntactic foams exhibit much lesser displacement as compared to the other foams under the same magnitude of blast loading; thus, the cenosphere aluminum alloy syntactic foams can be considered as suitable materials in blast response reduction. Similar to the steel plates, the composite sandwich panels for which the stiffener passes through the central node of the back sheet exhibit higher blast response reduction capability. Almost all the panels, $\mathrm{P}_{9}$ stiffener configuration shows the lowest peak displacement proving the effectiveness of such stiffener configuration in blast response mitigation.

4. Comparison between composite sandwich panels with foam and sand cores shows that the cenosphere aluminum alloy syntactic foams with the average sizes of cenosphere 90 and $200 \mu \mathrm{m}$ show superior blast response reduction capability than sand under the same magnitude of blast load.

Open Access This article is distributed under the terms of the Creative Commons Attribution License which permits any use, distribution, and reproduction in any medium, provided the original author(s) and the source are credited.

\section{References}

1. Guruprasad S, Mukherjee A (2000) Layered sacrificial claddings under blast loading part-I analytical studies. Int J Impact Eng 24(9):957-973

2. Guruprasad S, Mukherjee A (2000) Layered sacrificial claddings under blast loading part -II experimental studies. Int J Impact Eng 24(9):975-984 
3. Goel MD, Matsagar VA, Gupta AK (2011) Dynamic response of stiffened plates under air blast. Int J Protect Struct 2(1):139-155

4. Goel MD, Matsagar VA, Marburg S, Gupta AK (2012) Comparative performance of stiffened sandwich foam panels under impulsive loading. J Perform Constr Facil ASCE 27(5):540-549

5. Kadid A, Lahbari N, Fourar A (2007) Blast loaded stiffened plates. J Eng Appl Sci 2(2):456-461

6. Kadid A (2008) Stiffened plates subjected to uniform blast loading. J Civil Eng Manag 14(3):155-161

7. Sukontasukkul P, Mindess S (2003) The shear fracture of concrete under impact loading using end confined beams. Mater Struct 36(6):372-378

8. Wen HM, Reddy TY, Reid SR, Soden PD (1998) Indentation, penetration and perforation of composite laminates and sandwich panels under quasi-static and projectile loading. Key Eng Mater 141-143:501-552

9. Hanssen AG, Enstock L, Langseth M (2002) Close-range blast loading of aluminum foam panels. Int $\mathrm{J}$ Impact Eng 27(6):593-618

10. Tiwari R, Jain S, Chakraborty T, Matsagar V (2012) Dynamic response of reinforced concrete sacrificial walls under blast loading. In: Proceedings of the 10th world congress on computational mechanics (WCCM 2012), São Paulo, Brazil

11. Abrate S, Castanie B, Rajapakse YDS (2013) Dynamic failure of composite and sandwich structures. Solid mechanics and its applications. Springer, New York, USA

12. Zhu F, Lu G (2007) A review of blast and impact of metallic and sandwich structures. Electron J Struct Eng. doi:10.1177/ 1099636212460542

13. Hampsona PR, Moatamedia MA (2007) Review of composite structures subjected to dynamic loading. Int $\mathrm{J}$ Crashworthiness 12(4):411-428

14. Xue Z, Hutchinson JWA (2004) Comparative study of impulse-resistant metal sandwich plates. Int J Impact Eng 30:1283-1305

15. Thiagarajan G, Kadambi AV, Robert S, Johnson CF (2015) Experimental and finite element analysis of doubly reinforced concrete slabs subjected to blast loads. Int J Impact Eng 75:162-173

16. Zhou XQ, Kuznetsov VA, Hao H, Waschl J (2008) Numerical prediction of concrete slab response to blast loading. Int J Impact Eng 35(10):1186-1200

17. Banthia N, Bindiganavile V, Mindess S (2004) Impact and blast protection with fiber reinforced concrete. In: di Prisco M, Felicetti R, Plizzari GA (eds) 6th International RILEM symposium on fibre reinforced concretes. RILEM Publications SARL, Varenna, Italy

18. Gebbeken N, Döge T (2010) Explosion protection-architectural design, urban planning and landscape planning. Int J Protect Struct 1(1):1-22

19. Ngo T, Mendis P, Krauthammer T (2007) Behavior of ultrahigh-strength prestressed concrete panels subjected to blast loading. J Struct Eng 133:1582-1590

20. Dassault Systèmes Simulia Corporation (2011) Abaqus/ standard user's manual, version 6.11. Dassault Systèmes Simulia Corporation, Providence, USA

21. IS 456, 2000 (2005) Indian standard code for plain and reinforced concrete-code of practice
22. Wang ZL, Liu YS, Shen RF (2008) Stress-strain relationship of steel fiber-reinforced concrete under dynamic compression. Constr Build Mater 22:811-819

23. Goel MD, Chakraborty T, Matsagar VA (2012) Dynamic response of steel-sand composite stiffened plates under impulsive loading. J Battlef Technol 15(3):1-7

24. Belytschko T, Wong BL, Chiang H-Y (1992) Advances in one-point quadrature shell elements. Comput Methods Appl Mech Eng 96(1):93-107

25. Nascimbene R, Venini P (2002) A new locking-free equilibrium mixed element for plane elasticity with continuous displacement interpolation. Comput Methods Appl Mech Eng 191(17-18):1843-1860

26. Johnson GR, Cook WH (1985) Fracture characteristics of three metals subjected to various strains, strain rates, temperatures and pressures. Int J Fract Mech 21:31-48

27. Lubliner J, Oliver J, Oller S, Onate E (1989) A plastic-damage model for concrete. Int J Solids Struct 25(3):299-329

28. Silva PF, Lu B (2009) Blast resistance capacity of reinforced concrete slabs. J Struct Eng ASCE 135(6):708-716

29. Carreira DJ, Chu K (1986) Stress strain relationship for reinforced concrete in tension. Am Concr Inst J 82:797-804

30. Dusenberry D (2010) Handbook for blast-resistant design of buildings. Wiley, New Jersey, USA

31. Krauthammer T (2008) Modern protective structures. CRC Press, Boca Raton, USA

32. Song PS, Hwang S (2004) Mechanical properties of highstrength steel fiber reinforced concrete. Constr Build Mater 18:669-673

33. Pawade PY, Pande AM, Nagarnaik PB (2011) Effect of steel fibers on modulus of elasticity of concrete. Int J Adv Eng Sci Technol 7(2):169-177

34. Deshpande VS, Fleck NA (2000) Isotropic constitutive model for metallic foams. J Mech Phys Solids 48:1253-1276

35. Song B, Chen W (2005) Split Hopkinson pressure bar techniques for characterising soft materials. Lat Am J Solids Struct 2:113-152

36. Bryson JA (2009) Impact response of polyurethane. MS Thesis, Washington State University, Pullman, USA

37. Goel MD, Peroni M, Solomos G, Mondal DP, Matsagar VA, Gupta AK, Larcher M, Marburg S (2012) Dynamic compression behaviour of cenosphere aluminum alloy syntactic foam. Mater Des 42:418-423

38. Jackson JG, Rohani B, Ehrgott JQ (1980) Loading rate effects on compressibility of sand. J Geotechn Eng Div ASCE 106(8):839-852

39. TM5-1300 (1990) Structures to resist the effects of accidental explosions. US Departments of the Army and Navy and the Air Force, Washington, USA

40. Li G, Summers P, Clutter K, Bonaventure D (2012) Blast and impact resistant design of overhead protection structures. Struct Congr 167-176. doi:10.1061/9780784412367. 016

41. Gebbeken N, Ruppert M (1999) On the safety and reliability of high dynamic hydrocode simulations. Int $\mathrm{J}$ Numer Methods Eng 46:839-851

42. Børvik T, Hanssen AG, Langseth M, Olovsson L (2009) Response of structures to planar blast loads-a finite element engineering approach. Comput Struct 87:507-520

43. Luccioni B, Ambrosini D, Danesi R (2006) Blast load assessment using hydrocodes. Eng Struct 28:1736-1744 
44. Lacy JM, Novascone SR, Richins WD, Larson TK (2007) A method for selecting software for dynamic event analysis I: problem selection. Structural mechanics in reactor technology (SMiRT 19), August 2007. Idaho National Laboratory, Idaho Falls, USA

45. Riedel W, Mayrhofer C, Thoma K, Stolz A (2010) Engineering and numerical tools for explosion protection of reinforced concrete. Int J Protect Struct 1(1):85-101

46. Miller D, Pan H, Nance R, Shirley A, Cogar J (2010) A coupled Eulerian/Lagrangian simulation of blast dynamics. In: Proceedings of the IMPLAST 2010 conference October
12-14, 2010 Providence, (C) 2010 Society for Experimental Mechanics, Inc., USA

47. ASCE (2010) Design of blast resistant buildings in petrochemical facilities. Petrochemical Committee, Task Committee on Blast Resistant Design, ASCE, New York, USA

48. Smith PD (2010) Blast walls for structural protection against high explosive threats: a review. Int J Protect Struct 1(1):67-84

49. Goel MD, Matsagar VA (2014) Blast resistant design of structures. Pract Period Struct Des Constr, ASCE 19(2). doi:10.1061/(ASCE)SC.1943-5576.0000188 